\title{
A Task-Centered, Multiple Method Approach To Teaching Fraud Risk Assessment
}

\author{
Bonnie W. Morris, (email: Bonnie.Morris@mail.wvu.edu), West Virginia University \\ Ann B. Pushkin, (email: Ann.Pushkin@mail.wvu.edu), West Virginia University \\ William E. Spangler, (email: spangler@duq.edu), Duquesne University
}

\begin{abstract}
This manuscript provides an approach to teaching fraud risk assessment that is based on an analysis of the task and relevant research in education, cognitive psychology, and artificial intelligence. Fraud risk assessment (FRA) in financial reporting is an important and difficult task that must be performed in every financial statement audit. When auditors fail to detect fraudulent financial reporting (FFR), they are likely to become targets of shareholder and creditor litigation. Although FFR has a low occurrence rate considering the large number of financial statement audits conducted, it has a devastating impact on the investors, creditors and the profession.
\end{abstract}

\section{INTRODUCTION}

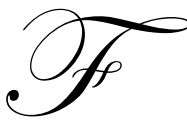

raud risk assessment (FRA) in financial reporting is an important and difficult task that must be performed in every financial statement audit. When auditors fail to detect FFR, they are likely to become targets of shareholder and creditor litigation and increased regulatory scrutiny, as evidenced by the Sarbanes Oxley Act of 2002. Consequently, improving auditor skill in assessing the risk of FFR has important implications for maintaining the reputation of the profession.

Fraudulent financial reporting (FFR) has a low occurrence rate considering the large number of financial statement audits conducted, but it has a devastating impact on the investors, creditors and the profession. The Report of the National Commission on Fraudulent Financial Reporting states, "Public confidence in the fairness of financial reporting is critical to the effective functioning of the securities markets." (National Commisssion on Fraudulent Financial Reporting, 1987). KPMG's 2003 Fraud Survey reports that the average cost of financial reporting fraud is more than $\$ 250$ million per incident.

Assessing the likelihood of FFR is a very difficult task, however. Loebbecke, Eining and Willingham describe it as, "...a multi-attribute, high-level-judgment task that requires knowledge, experience, and reasoning." (Loebbecke et al., 1989, p. 3). Although FRA is the type of task that is best learned through experience, the ability of auditors to learn "on-the-job" is limited due to the low occurrence rate of FFR and because the impact of failure is so great. Because of the complexity of the fraud risk assessment (FRA) task, undergraduate auditing courses seldom provide in-depth coverage. This suggests the need for teaching approaches that address complex tasks.

This manuscript describes an approach to teaching FRA that is based on an analysis of the task and on relevant literature in educational and cognitive psychology and artificial intelligence. We provide a framework for teaching the topic and give an example of how the framework can be implemented.

The remainder of the paper is organized as follows. We begin with an analysis of the core fraud risk assessment task, which motivates the critical need for task competency in practice. The analysis also links the task and learning of the task - to the extant literature in educational psychology, cognitive psychology and artificial 


\section{Number 3}

intelligence related to memory and knowledge structures. We follow with a description and explanation of the teaching techniques used, including the sequence of classroom assignments and how each assignment addressed progressively-higher critical thinking skills in Bloom's taxonomy (1956). We then discuss assessment issues, focusing on the nature of professional judgment and the role of judgment in guiding audit planning - arguably the most critical, and difficult, component of the overall audit task. We conclude with implications for future research including how this approach to learning might impact the design of auditor decision support systems.

\section{TASK ANALYSIS AND LITERATURE REVIEW}

To develop our approach to teaching FRA, we drew on three disciplines: the professional auditing standards and related auditing research, Bloom's taxonomy of educational objectives from the educational psychology discipline, and research from cognitive psychology/artificial intelligence related to the nature of expertise, memory and knowledge structures.

Decision tasks can be characterized as a set of inputs, rules for processing the inputs into an output, and a feedback loop that may modify the set of inputs or the processing rules. Some tasks, like calculating payroll, are highly structured. The inputs are well known; the rules for processing are fully specified, and there are rarely any exceptions to the rules. Other tasks, like FRA, are described as ill structured or semi-structured. Ill structured tasks lack a strong, well-defined domain model that explains the relationship between the inputs and the outcome. Also, there often is a lack of consensus about the relevant inputs and the processing rules. This is the case with the FRA task. There is disagreement among accounting researchers and standard setters as to the importance of various inputs and in the weights given to inputs in arriving at a risk assessment.

Elliot and Willingham (1980) defined "red flags" as, "conditions believed to be commonly present in events of fraud." Albrecht and Romney (1986) identified 87 factors as red flags for management fraud. Of those factors, 31 were found to be significant as predicators of management fraud. Loebbecke and Willingham, (1988) proposed an "assessment model" to aid auditors in assessing the risk of management fraud. Under this model, fraud risk factors are classified into three categories: conditions that make it possible to commit fraud (C), motivation for persons in authority to commit fraud (M), and attitude or lack of personal integrity of persons in authority that would allow them to commit fraud (A). The model calculates the probability of management irregularity $(\mathrm{MI})$ as: $\mathrm{P}(\mathrm{MI})=\mathrm{f}(\mathrm{C}, \mathrm{M}, \mathrm{A})$ where $\mathrm{P}(\mathrm{MI})=0$ if $\mathrm{C}$ or $\mathrm{M}$ or $\mathrm{A}=0$. In other words, factors from all three categories must be present in order to assess a high probability of management fraud. Loebbecke et al., (1989) identified 55 fraud risk factors, which they categorized according to the Loebbecke and Willingham (1988, as reported in Loebbecke et al., 1989) model. They also categorized the factors as primary, secondary, or tertiary with respect to importance.

There have been numerous other academic studies of fraud prediction based on fraud risk factors. The studies utilized such techniques as cascaded logit (Bell et al., 1995), neural networks (Fanning et al., 1995, Fanning et al., 1998). In general, these techniques have yielded lower predictive accuracy rates for fraud prediction than the naïve model (always predicts non fraud). Because the cost of Type I and Type II errors are quite different for fraud prediction, the overall prediction rate is not the best way to evaluate such models. Most fraud prediction models make some allowance in the model or in the interpretation of the output to adjust for the higher cost of failing to predict fraud. There is, however, no consensus on how to account for the trade offs between Type I and Type II errors.

When the framework for teaching FRA was being developed, the most current auditing standard that addressed fraudulent financial reporting was Statement of Auditing Standard No. 82 (SAS No. 82), "Consideration of Fraud in a Financial Statement Audit." (AICPA 1997) SAS No. 82 has since been superseded by SAS No. 99 with the same title. The importance of considering fraud risk assessment is also emphasized in Sarbanes-Oxley Act and the Public Company Accounting Oversight Board's (PCAOB) Auditing Standard No. 2 which were issued after the framework for teaching FRA was developed. The approach to teaching FRA is still relevant for SAS No. 99 and PCAOB Auditing Standard No. 2. 
SAS 82 provided a list of fraud risk factors that should be considered by the auditor, but did not provide guidance on how to combine the factors into a risk assessment. In fact, SAS No. 82 stated, "Fraud risk factors cannot easily be ranked in order of importance or combined into effective predictive models." (AICPA 1997, ๆ21) The Standard discussed the Loebbecke and Willingham (1988) approach, but cautioned against indiscriminate use. Instead, the Standard reminded auditors that they must "exercise professional judgment when considering risk factors individually or in combination...” (AICPA 1997, II21).

Auditing standards emphasize the assessment of fraud risk as a step in the audit planning process. The standards require auditors to prepare an audit plan that effectively addresses the fraud risk factors that are present.

\section{COGNITIVE PSYCHOLOGY AND ARTIFICIAL INTELLIGENCE}

Research in cognitive psychology and artificial intelligence has found that when individuals are faced with tasks that lack a strong domain model, i.e., that have incomplete, poorly-defined or inconsistent rules, they resort to case-based reasoning (CBR) (Kolodner 1993; Ashley \& Rissland, 1987; Tversky \& Kahneman, 1974). CBR is a method of reasoning by analogy to past cases or experiences. Instead of performing the task by finding and applying the most appropriate fundamental principles, a decision maker finds and applies knowledge of the most relevant and similar prior cases (Mukhopadhyay et al., 1992). The mental model for the task is embodied in the indexing scheme rather than in weights for combining variables.

Case-based reasoning is especially effective when there are a large number of potentially relevant factors and there are interaction effects. That is, different aspects of the cases are differentially important in different contexts. SAS No. 82 specifically notes that contextual factors such as size, complexity and ownership characteristics affect the significance of fraud risk factors (AICPA 1997, I14).

Accounting firms recognize the usefulness of case-based reasoning. Firms typically maintain precedent case files that provide exemplars of problems and solutions that the auditing staff is encouraged to use in preparing for and conducting an audit engagement (Salterio 1996). The large international accounting firms encourage auditors to search for precedents (Danos et al., 1989; Salterio, 1996).

The problem with using CBR for fraud risk assessment is that it occurs so infrequently. In a survey of partners from one large international accounting firm, Loebbecke et al. (1989) found that on average they had encountered material management fraud fewer than three times. This suggests that FRA is difficult to learn on the job. It requires formal training.

\section{RESEARCH IN ACCOUNTING EDUCATION AND EDUCATIONAL PSYCHOLOGY}

Over the years, accounting instructors have been encouraged to adopt new teaching methods to develop critical thinking skills in our students. Traditional methods of teaching accounting have been criticized for placing too much emphasis on declarative and procedural knowledge and too little emphasis on developing the analytical abilities required in practice (Big Eight White Paper 1989; American Education Change Commission 1990; Frecka, 1992).

The development of analytical abilities is essential, in part, because auditors must make professional judgments in many situations where there is no single correct answer. Tasks such as evaluating internal controls, interpreting trend analyses, assessing the reasonableness of management's estimates and assessing the likelihood of fraudulent financial reporting require higher-level cognitive skills. Prior research has focused primarily on developing critical thinking elements using a single teaching method to develop these skills in accounting students. For example, several studies have examined the impact of the case method on critical thinking skills, while others have examined the impact of group collaboration and report writing (Campbell and Lewis, 1991; Craig and Amernic, 1994; Martin, 1994). Kimmel in turn proposed a framework for assigning critical thinking elements to particular accounting courses based on student intellectual stage and course content. (Kimmel, 1995). 
However, single teaching methods may be inadequate for the development of requisite cognitive skills. Bonner (1999) instead argues that in order to create appropriate conditions for certain learning objectives, instructors should employ combinations of teaching methods.

The framework for teaching FRA discussed in this paper is based on a similar premise. Rather than focus on a single method applied across an entire accounting course, we instead use multiple methods applied to a single task within a course. This approach entails presenting students with a series of assignments intended to engage critical thinking at progressively higher levels, as characterized by Bloom's taxonomy (Bloom et al., 1956).

Bloom's taxonomy of educational objectives identifies six major levels or categories of learning (see Table 1). The most basic category is 1) knowledge, which essentially entails memorization or identification of facts. After knowledge comes 2) comprehension, which focuses on meaning and intent, 3) application, which applies existing knowledge to new situations, 4) analysis, which enables deeper understanding through decomposition of concepts into components, 5) synthesis, the final level of learning which combines components to form original conclusions, and 6) evaluation which is used in conjunction with the other five categories.

Table 1

The Major Categories Of Bloom's Taxonomy

\begin{tabular}{|l|l|}
\hline Category & Behavior \\
\hline Knowledge & $\begin{array}{l}\text { Consists of memorization or identification of facts. Knowledge of specifics, terminology, ways and } \\
\text { means of dealing with specifics, conventions, trends, classifications and categories, criteria, } \\
\text { methodology, universals and abstractions in a field. }\end{array}$ \\
\hline Comprehension & $\begin{array}{l}\text { Focuses on the meaning and intent of material. Ability to paraphrase, interpret, and extrapolate } \\
\text { information (to determine implications, consequences, and effects. }\end{array}$ \\
\hline Application & Apply prior knowledge to new/different situations and tasks. \\
\hline Analysis & $\begin{array}{l}\text { Breakdown a concept into components. Necessary where deeper understanding is required and before } \\
\text { decisions can be reached and problems solved. Includes differentiating between objective data and value } \\
\text { judgment. }\end{array}$ \\
\hline Synthesis & $\begin{array}{l}\text { Use parts or elements to form original conclusions. Includes the ability to create or derive statements to } \\
\text { explain or classify data or a situation. }\end{array}$ \\
\hline Evaluation & Application of criteria to judge various situations or conditions that are encountered. \\
\hline
\end{tabular}

\section{The Approach}

In simplest terms, the learning objectives can be divided into two parts: what students should be able to do as a result of the learning experience, and what knowledge they need to acquire in order to be able to do such tasks.

Based on an analysis of the task, we concluded that students should be able to:

- $\quad$ assess the significance of various fraud risk factors

- $\quad$ communicate or explain how individual factors affect the global risk assessment

- $\quad$ distinguish between fraud prediction and fraud risk assessment

- combine risk factors to make a global risk assessment based on all the information available to them

In order to be able to do these tasks, students need to know the following:

- $\quad$ The importance of the task

- $\quad$ The key points of the auditing standard

- $\quad$ The key results of relevant academic research 
- $\quad$ The difference between fraud prediction and fraud risk assessment for audit planning

- How fraud risk assessment fits in the overall audit task

The teaching methodology includes multiple methods. There should be an emphasis on the use of cases and the development of an effective indexing scheme. Assignments should be designed to require students to:

- $\quad$ Memorize certain facts (knowledge)

- $\quad$ Restate, paraphrase, and summarize to demonstrate comprehension (comprehension)

- $\quad$ Reason hypothetically about the effect of various combinations (application)

- $\quad$ Critique rules or models and challenge assumptions (analysis)

- $\quad$ Classify and explain (analysis)

- $\quad$ Apply criteria to judge new situations where the outcome is uncertain (synthesis)

\section{Classroom Assignments}

Based on framework, seven student activities were identified to help students acquire prerequisite knowledge, build knowledge structures, understand the context in which fraud risk assessment takes place and develop the cognitive skills necessary to perform fraud risk assessment. Table 2 lists the activities and relates them to the major learning categories of Bloom's Taxonomy.

Table 2

Relationships Of Assignments To The Major Categories Of Bloom's Taxonomy

\begin{tabular}{|c|c|c|c|c|c|c|}
\hline Assignments & Knowledge & $\begin{array}{l}\text { Comprehensio } \\
\text { n }\end{array}$ & Application & Analysis & Synthesis & Evaluation* \\
\hline 1. Watch Videos & & & & & & \\
\hline 2. Study SAS No. 82 & & & & & & \\
\hline 3. Access AICPA Web Site & & & & & & \\
\hline 4. Wosepka Case & & & & & & \\
\hline 5. Lincoln S\&L Case & & & & & & \\
\hline 6. Red Flags Questionnaire & & & & & & \\
\hline 7. In-Class Exercise & & & & & & \\
\hline
\end{tabular}

*Note: Evaluation is a "floating" category that can be used in conjunction with any of the other categories.

The design and sequencing of student assignments are consistent with Bloom's taxonomy. Assignments were made that would take the students from the lowest cognitive skills level to the highest level of critical thinking. It is well established that individuals cannot attain a high level of critical thinking without first experiencing the lowest levels of knowledge and comprehension. Each assignment was developed to enhance the students' critical thinking skills in the context of the auditor's responsibility to assess the likelihood of fraud in a financial statement audit.

\section{Activity 1 - Acquiring Knowledge Of Fraud And Setting The Context For The Task}

First, students were shown the video "Cooking the Books: What Every Accountant Should Know About Fraud" [National Association of Certified Fraud Examiners, 716 West Avenue, Austin, Texas 78701, (C) 1991] which features three highly visible frauds. These frauds were the ZZZ Best Case, the Regina Vacuum Company fraud, and the EMS Securities fraud. Although the production of this video was prior to SAS Nos. 82 and 99, the cases dealt with fraudulent financial reporting and misappropriation of assets. The cases presented in the video focused primarily on the behavioral aspects of both the auditors and the perpetrators of the frauds rather than on the auditor's assessment for the risk of fraud or the procedural aspects in a financial statement audit. The video made the students aware of the concept of fraud in real world situations and the importance of fraud from a societal point of view. This first assignment set the stage to understand the importance of the auditor's responsibility to assess and detect fraud in 

develop higher-level cognitive skills.

Stories, such as those in the video, can help transform abstract concepts into concrete images. The stories conveyed the importance of fraud risk assessment better than having an instructor say it. The video also contributed to the development of the knowledge structures necessary to support the fraud risk assessment by providing students with a set of "memories" of fraud cases. The stories are a surrogate for personal experiences that are used to build knowledge. Although video cases are not as rich in detail as personal experiences, they generally are richer and more compelling than simple rules. Furthermore, the use of stories to supplement personal experience is common in the auditing profession.

\section{Activity 2 - Acquiring Knowledge Of SAS No. 82 And Organizing Knowledge Structures}

The next assignment required the students to study the auditing standard. Before students can apply a standard, they need to know the concepts and directives contained therein. Students were required to read the standard, but they were specifically instructed not to memorize the fraud risk factors. Instead, students were asked to consider the different categories of factors and the nature of the factors within each category.

Discussion of SAS No. 82 in the classroom focused on the auditor's responsibility 1) to assess the risk of fraud in every financial statement audit and 2) to ensure that the audit program addresses the existing fraud risk factors. During the discussion, students were expected to interpret the SAS in their own words. The students also were made aware that SAS No. 82 did not provide guidance on "how" the existing fraud risk factors should be addressed in an audit plan. Students also discussed the danger that auditors could potentially consider only the factors listed and would overlook existing factors not included in SAS No. 82.

The reading assignment and classroom discussions concerning SAS No. 82 expanded the students' knowledge with respect to definitions and the auditor's responsibility to assess fraud risk factors in a financial statement audit. This activity addressed the knowledge level in Bloom's Taxonomy. Additionally, the classroom discussions contributed to the comprehension of the audit task because students paraphrased the basic ideas and concepts promulgated in SAS No. 82.

Another part of the class discussion focused on how the fraud risk factors relate to motivation, opportunity, and management's attitude and integrity. The instructor briefly summarized some of the academic research related to fraud detection. For instance, Loebbecke, Eining and Willingham (Loebbecke et al., 1989) proposed a model in which the probability of fraud depends on the existence of three factors. First, conditions must exist that would allow fraud to occur. Second, there must be a motive to commit fraud. Third, the involved individuals must have a level of integrity that would allow them to commit fraud.

Introduction of the research served two purposes. First, it made students aware of academic accounting research as a source of information to aid practitioners and improve decision-making. Second, it helps satisfy the students' need for rules. It may be a surprising to some students to realize that the professional standards do not provide explicit "cookbook" rules for combining risk factors. When students are faced with the prospect of having to make risk assessments in accordance with SAS No. 82 without explicit rules for doing so, they are likely to experience a great deal of anxiety. The Loebbecke et al. (1989) model (LEW) provides them with an initial rule for combining risk factors into a risk assessment. The LEW model, however, was used in later exercises to help students explore the role of and limitations of such models in complex domains.

Another objective of the assignment was to aid the students in creating an indexing scheme for the cases they had stored in memory. Indexes to prior cases are an important part of reasoning from prior experiences. The ability to relate current events to past experiences is dependent on the ability to recall - via memory indexes -- the appropriate past cases when needed. The more ways in which a case is indexed or linked in memory, the more likely it is to be recalled when a similar case is encountered (Schank, 1990). Recall of prior cases, in turn, aids in the interpretation 
and comprehension of new - but similar - events. The fraud risk categories and the discussion of the need to interpret the factors in light of the context (e.g., public or privately held) provided the students with a means of organizing their knowledge. Having students engage in the activity of thinking about categories of risk factors as opposed to simply memorizing a list should also contribute to the development of effective knowledge structures.

\section{Activity 3 - Reinforcing Concepts}

For homework, each student was required to access and study a page on the AICPA' s Web site, "Fraud in a Financial Statement Audit -- A Student Educational Supplement" and complete an exercise. The learning objectives focused on the student's ability to state, explain, and articulate the concepts set forth in SAS No. 82. The mini-cases presented in the Web site asked students to identify the types of fraud described, the motivational and opportunity factors existing in the case, and to interpret why the auditor ignored the warning signs of fraud. All of these case requirements reinforced the knowledge and comprehension of the concepts promulgated in SAS No. 82. Before accessing the Web site, students were told that the material covered in the site would be discussed in the classroom and that a quiz on SAS No. 82 would be given. The Quiz gave the students an opportunity to demonstrate their knowledge and comprehension of the concepts promulgated in SAS No. 82 and it provided motivation for the students to expend effort on the task.

\section{Activity 4 - Setting The Context And Applying Concepts}

The next assignment required the students to complete a case from the Professor/Practitioner Case Development Program (P/P Cases) sponsored by the AICPA Academic and Career Development Division. The case, United States of America v. Harold Wosepka: "A Case Involving Fraudulent Financial Reporting," was written by Norman J. Gierlasinski and Robert L. Fuhriman [Case No. 97-11]. The Wosepka case depicts how fraudulent financial information was used to obtain \$1,950,000 from the Small Business Administration. Harold T. Wosepka obtained the Small Business Investment Company funds to operate as a federally sponsored bank. However, Wosepka converted such funds for his own and his co-conspirators' personal benefit.

The case does not describe the red flags that tipped-off the investigators in a routine examination. Rather, it provides students with factual information and general descriptions of how the SBA investigator and FBI agents conducted the investigation and traced the movement of funds. Students were not required to determine how the funds should be traced for this particular situation, but they were asked to discuss the ways (in general) that funds can be traced. In terms of Bloom's taxonomy, the student had to demonstrate and apply knowledge and comprehension in this case.

The Wosepka case really served a more important purpose than just learning about tracing funds, however. One of the problems that auditing students have is understanding how the individual audit tasks fit together--or as practitioners like to say "getting the big picture." The initial video cases provided a general context for the importance of fraud risk assessment. The SAS provided further support for the importance of the task and identified criteria that are useful in conducting the task. The Wosepka case (and the Lincoln Savings and Loan case that follows) illustrates particular audit procedures for collecting and evaluating audit evidence. The cases show students that risk assessment is not the end of a task, but simply one step in the overall audit process. Risk assessment guides the design of the audit plan, which leads to the collection and evaluation of evidence.

\section{Activity 5 - Acquiring Experiential Knowledge And Applying Case-Based Reasoning}

Students were then asked to complete a second P/P case, Lincoln Savings and Loan, written by Mary Nisbet and Donald R. Loster [Case No. 96-05]. The Lincoln Savings and Loan case required students to compute financial ratios under three different assumptions associated with the case (an application activity) and then determine the adequacy of the financial information for investment decisions (analytical behavior). One question asked the students to evaluate the advice a CPA gave Lincoln Savings \& Loan and to assess possible issues not considered by the CPA (an example of the evaluation level of cognitive behavior). 
The Lincoln Savings and Loan case added to the students' knowledge base. If researchers are correct in saying that fraud risk assessment is the type of task is usually learned through experience, then providing additional "experience" (even surrogate experience in the form of business cases) should benefit the students. Furthermore, as noted above, such cases help students understand the role of risk assessment in the overall audit process.

\section{Activity 6 - The Nature Of Professional Judgment - Challenging Assumptions}

The sixth activity returned to the fraud risk factors. Students were given a "red flags" questionnaire developed by prior researchers who sought to develop models to improve the prediction of fraudulent financial reporting. During classroom discussion, students were asked to compare and contrast the questionnaire items with the risk factors promulgated in SAS No. 82. The students were asked to categorize each factor in the questionnaire in terms of motivation, opportunity, and management's integrity. Then, the classroom discussion focused on the importance of considering the combination of fraud risk factors rather than considering each factor individually. To illustrate this point, the instructor and the students constructed combinations of risk factors that seemed to contradict the LEW model. That is, they selected combinations of risk factors that included items from each of the three categories that did not appear to represent a high risk of FFR. Likewise, they identified combinations that did not have all three categories present that did seem to reflect a high risk of FFR.

Challenging assumptions, reasoning hypothetically, and critiquing rules or models and testing their limits are important elements of the analysis and evaluation levels of critical thinking. The task was intended to provide insight into the fraud risk assessment task. Additionally, it is hoped that by practicing these skills in the fraud risk assessment task, students will be encouraged to apply similar reasoning in other contexts.

\section{Activity 7- Dealing With Uncertainty - Analysis, Synthesis, Evaluation}

There was no uncertainty about the presence of fraud in either the Wosepka or the Lincoln Savings and Loan case. Students knew that the cases involved fraudulent financial reporting and misappropriation of assets. As a result, there was no opportunity or need for the students to synthesize data to form a conclusion as to whether fraud existed. The final class exercise was designed to address this shortcoming.

Students were told to assume they were practicing CPAs who had been asked to assess a completed "Red Flags" questionnaire for fifteen clients. For each client, the students were provided the red flags that actually existed for that client. Students did not know the outcome of the cases. Therefore, it was necessary for them to synthesize facts. The students had been told that there was a mix of clients -- some with and some without fraudulent financial reporting -- and that they should not make any assumptions about the number of fraud or non-fraud clients. Students were asked to assign a number between zero and 100 to represent their assessed level of risk for FFR. For each client, they had to write a brief analysis or explanation of their risk assessment.

For this exercise, student grades were based on the quality of the explanations and the extent to which the explanations were consistent with their numeric assessments of the likelihood of fraud. Students were asked to assign a numeric value rather than "High," "Medium," or "Low" to encourage them to make more detailed comparisons between cases. Students who explained their assessments by merely listing the fraud risk factors that were present were given a low grade (and were judged not to have demonstrated critical thinking). Students who drew inferences about the interaction of the risk factors, discussed the impact of fraud risk factors that were not present or who reasoned hypothetically about organizational characteristics earned higher grades (and were judged to have demonstrated critical thinking).

The ability to explain or justify one's actions is an important part of professional practice. For example, the audit plan (and the related time budget) must be explained in terms of perceived client risks to the audit partner, peer reviewers, and possibly in court if the FFR is not detected during the engagement. Assessment and justification are activities in the analysis and synthesis levels of Bloom's taxonomy. Justification is also an activity in the evaluation level of the taxonomy. 
Also, in Activity 7, students were asked to predict the actual outcome of the case. This was done to reinforce the point that there is a difference between predicting FFR and assessing the likelihood of FFR as part of the audit process. To motivate the students, bonus points were awarded for correct predictions.

\section{STUDENT PERFORMANCE RESULTS AND IMPLICATIONS FOR FUTURE RESEARCH}

Because of time constraints we were unable to do pre-test/post-test comparisons of the performance of the students. Many of the prior research studies utilize the data from (Bell et al., 1995). The result of Bell's logit model is the standard against which those fraud prediction models are measured. Because the cases our students evaluated were also taken from Bell's data set, we compared our student performance against Bell's results. Table 3 compares individual student assessments of fraud with logit results. Student performance compares favorably with that of logit model, both in the percentage of correct assessments and in the types of errors committed.

In order to compare student performance with the logit likelihood assessments, student assessments of fifty percent or greater were considered fraud, while those less than fifty percent were considered non-fraud. The results were then compared with the actual incidence of fraud. On a case-by-case comparison, students collectively outperformed logit in three cases, logit outperformed the students in two cases, and they agreed on the remaining cases. In the two cases in which the majority of students were bested by logit, the students committed a Type I error. They assessed a high likelihood of fraud given the case factors, even though incidentally fraud was not actually observed in those cases. By contrast, in those cases in which the students outperformed logit, logit committed a Type II error -- it predicted non-fraud when fraud actually was present, which arguably is the more serious error.

Table 3

Comparing Student And Logit Type I And Type II Errors

\begin{tabular}{|c|c|c|c|c|}
\hline & Correct & Type I & Type II & Total \\
\hline Student Assessment & & & & 49 \\
\hline Number & 210 & 126 & $17.04 \%$ & $100.00 \%$ \\
\hline Pct & $51.85 \%$ & $31.11 \%$ & 114 & 0 \\
\hline Student Prediction & & & & 405 \\
\hline Number & 195 & 96 & $28.15 \%$ & $100.00 \%$ \\
\hline Pct & $48.15 \%$ & $23.70 \%$ & 6 & 0 \\
\hline Logit & 6 & & $40.00 \%$ & 15 \\
\hline Number & $40.00 \%$ & $20.00 \%$ & $100.00 \%$ \\
\hline Pct & & 3 & & \\
\hline
\end{tabular}

Note: Type I Error indicates that the student predicted fraud for cases where there was no fraud. Type II Error indicates that the student predicted no fraud for cases where there was fraud.

Great care must be taken in interpreting the results of the comparison between student assessments and the logit model. Students were highly sensitized to fraud and to the fact than Type II errors are so costly. Therefore, the student results could be partially attributed to demand effects. Furthermore, students are not subjected to real world budget pressures to keep audit fees down. Accordingly, students may not have been as concerned about committing Type I errors as practitioners.

In addition to assessing the risk of fraud, students were asked to predict the actual outcome of each case. Again the students performed very well. On a case-by-case comparison of fraud prediction, the students collectively performed nearly identically to logit. That is, a majority of students agreed with the logit prediction in 14 of the 15 cases. Notably, in the single divergent case, the students collectively were correct in predicting fraud, while logit was incorrect (a Type II error). 
As expected, students were less conservative in predicting fraud than in assessing the likelihood of fraud for audit purposes. Nevertheless, students performed well in comparison to the logit model. This study provides only preliminary results based on a limited number of cases. Accordingly, further research is needed to examine this issue explicitly.

The broader issue of student performance evaluation also is a potential area of future research. Because we did not perform pre- and post-tests of overall student performance, and therefore did not measure improvement in critical thinking skills per se, we are limited in the conclusions that we can draw about the effectiveness of activities to improve critical thinking skills. In the current study, the evaluation of student performance was based on the ability of the student to perform a difficult auditing task that requires critical thinking. Toward this end, the following four activities determined individual grades: 1) a multiple-choice quiz covering the major concepts presented in SAS No. 82; 2) paraphrasing the requirements of the Standard; 3) analyses of FFR cases presented in written reports; and 4) the student's written risk assessments for FFR in 15 cases. Determining grades based on quizzes, the paraphrasing of contextual information, and written reports are traditional ways of evaluating student performance. Grades from these activities generally have a specific answer or a suggested solution. On the other hand, assessing student performance in tasks that require professional judgment is difficult. Evaluation of the students' risk assessments had to be based on the quality and consistency of their explanations offered to support their probability levels for fraudulent financial reporting (as they would be in practice). Student performance in justifying the fraud assessments varied. Although most students were able to make inferences about the interactions among the risk factors present (or absent) in a case, a few relied simply on listing the factors from the questionnaire. A mere listing of existing risk factors to justify an assessment for fraud was not considered a high quality answer for grading purposes.

In retrospect, other 'lessons learned' regarding the structuring of the learning activities became apparent. For example, although the overall student performance was good, some students might have benefited from more practice in performing fraud risk assessments and writing justifications before they completed the final exercise. In class, the students discussed the risk factors and the impact on the assessment, but did not practice writing justifications. Writing an explanation in a professional manner is a difficult task in itself. In addition, providing the students with clearer reasons for doing the tasks might have helped enhance their cognitive skills. In the current study, learning outcomes were stated in the traditional way: "Students should be able to state... identify... paraphrase... apply..." Instead, it may have been better to express the learning objectives in terms of the development of knowledge structures. By discussing the nature of expert judgment, reasoning by analogy, and strategies for reading and interpreting the professional standards, students may have gained greater insight to the nature of professional judgment. Having greater insight to professional judgment increases the likelihood that students will apply those strategies and techniques to other auditing tasks.

\section{REFERENCES}

1. Albrecht, S. \& Romney, M. (1986). Red-flagging Management Fraud: A Validation, Advances in Accounting 3, 323-333.

2. American Education Change Commission. (1990). Position Statement No. One: Objectives of Education for Accountants. Issues in Accounting Education, 5, 307-312.

3. American Institute of Certified Public Accountants (AICPA). (1997). Consideration of Fraud in a Financial Statement Audit. Statement on Auditing Standards No. 82. New York, NY: AICPA

4. Ashley, K. \& Rissland, E. (1987). Compare and contrast: A test of expertise, Proceedings of AAAI-87, 273278, Seattle, WA: American Association for Artificial Intelligence.

5. Bell, T. B., Carcello, J. V., \& Willingham, J. J. (1995). Development of a decision aid for assessing the likelihood of fraudulent financial reporting. Working Paper. KPMG Peat Marwick.

6. Big Eight White Paper. (1989). Perspectives on education: capabilities for success in the accounting profession. New York: Arthur Andersen and Co., Arthur Young, Coopers and Lybrand, Deloitte Haskins and Sells, Ernst and Whinney, Peat Marwick Main and Co., Price Waterhouse, and Touche Ross. 
7. $\quad$ Bloom, B., Englehart, M., Furst, E., Hill, W., \& Krathwohl, D. R. (eds). (1956). Taxonomy of educational objectives: The classification of educational goals. Handbook I: Cognitive Domain. New York: D. McKay Co., Inc.

8. Bonner, S. E. (1999). Choosing teaching methods based on learning objectives: An integrative framework. Issues in Accounting Education, 14, 11-36.

9. Campbell, J. E. \& Lewis, W. F. (1991). Using cases in accounting classes. Issues in Accounting Education, 6, 276-283.

10. Craig, R. \& Amernic, J. (1994). Roleplaying in a conflict resolution setting: description and some implications for accounting. Issues in Accounting Education, 9, $28-44$.

11. Danos, P.D., Eichenseher, J. W., \& Holt, D. L. (1989). Specialized knowledge and its communication in auditing, Contemporary Accounting Research, 6, 91-109.

12. Elliott, R.K. \& Willingham, J. J. (1980). Management Fraud: Detection and Deterrence, Princeton, N.J.: Petiocelli Books.

13. Fanning, K., Cogger, K. O., \& Srivastava, R. (1995). Detection of management fraud: a neural network approach. Intelligent Systems in Accounting, Finance and Management, 4, 113-126.

14. Fanning, K. M. \& Cogger, K. O. (1998). Neural network detection of management fraud using published financial data. Intelligent Systems in Accounting, Finance and Management, 7, 21-41.

15. Frecka, T. J. (1992). Editor's summary. Critical Thinking, Interactive Learning, and Technology: Reaching for Excellence in Business Education. Chicago, IL: Arthur Andersen \& Co., 1-15.

16. Kimmel, P. (1995). A framework for incorporating critical thinking into accounting education. Journal of Accounting Education, 13, 299-318.

17. Kolodner, J. (1993). Case-Based Reasoning. San Francisco CA: Morgan Kaufmann Publishers,

18. KPMG LLP (2003). Fraud Survey 2003. Montvale NJ: KPMG LLP, 4.

19. Loebbecke, J. K., Eining, M. M., \& Willingham, J. J. (1989). Auditors' experience with material irregularities: Frequency, nature, and detectability. Auditing: A Journal of Practice and Theory, 9, 1-28.

20. Loebbecke, J. K. \& Willingham, J. J. (1988). Review of SEC accounting and auditing enforcement releases. Unpublished working paper. KPMG. As cited in Loebbecke et al. 1989.

21. Martin, J. R. (1994). A controversial-issues approach to enhance management accounting education. Journal of Accounting Education, 12, 59-76.

22. Mukhopadhyay, T., Vicinanza, S.S., \& Prietula, M.J. (1992). Examining the feasibility of a case-based reasoning model for software effort estimation, MIS Quarterly, 16, 155-171.

23. National Commisssion on Fraudulent Financial Reporting. 1987. Report of the National Commission on Fraudulent Financial Reporting. New York: Committee of Sponsoring Organizations of the Treadway Commission.

24. Salterio, S. (1994). Researching for accounting precedents: learning, efficiency, and effectiveness, Contemporary Accounting Research, 11, 515-542.

25. Schank, R. C. (1990). Tell Me a Story: A New Look at Real and Artificial Memory. New York: Charles Scribner's Sons.

26. Tversky, A. \& Kahneman, D. (1974). Judgment under uncertainty: Heuristics and biases. Science, 185, 1124-1131. 
Journal of College Teaching \& Learning - March 2006

Volume 3, Number 3

\section{NOTES}

